\title{
Research of making compound of wasted uniform material and biomass anti-bacterial-oil
}

\author{
Megumi Sekkuden ${ }^{1}$, Toshio Yamamura ${ }^{2}$, Tatsuo Okazawa ${ }^{3}$, Koichi Goda ${ }^{4}$ \\ Kazuhiko Ogawa ${ }^{5}$, Seiji Kakuta ${ }^{6}$, and Toshihiro Okabe ${ }^{6}$ \\ 1 The United Graduate School of Agricultural Sciences, Iwate University 3-18-8 Ueda Morioka 020-8550 Japan \\ Tel: +81-3-3861-7270 Fax: +81-3-3861-7270 E-mail:kuma_mania2006@yahoo.co.jp \\ ${ }^{2}$ Yamamura Professional Engineering Office 18-5-702 Oimatsucho Nishinomiya Hyogo 662-0085 Japan \\ ${ }^{3}$ Yamaguchi University 2-16-1 Tokiwadai Ube Yamaguchi 755-8611 Japan \\ ${ }^{4}$ Tokyo Metropolitan Agriculture and Foresty Research Center 3-8-1 Fujimicho Tachikawa Tokyo 190-0013 Japan \\ ${ }^{5}$ Hiroshima Polytechnic Center 2-15-55 Hikari-machi Higashi-ku Hiroshima City 730-0825 Japan \\ ${ }^{6}$ Aomori Prefectural Industrial Technology Research Center 221-10 Yamaguchi Nogi Aomori 030-0142 Japan
}

The purpose of this research is to develop the recycling methods of the uniform material, which is the mixture of wool and polyester and had been abandoned up to now because the way of reuse had not been developed. As a basic research, we repeated the experiment to make uniform materials compound by soaking them in the mixture of PVA(polyvinyl alcohol) of the high polymerization degree and biomass oil (i.e. Hiba Japanese cypress oil and wood vinegar oil) in various densities. As a result it turned out that the characteristic changes variously by the difference of PVA consistency and biomass anti-bacterial oil, and that it brings the positive multiplier effect to the qualities of uniform material

Key words: Uniform, PVA, Agriculture, Greening, Environment

\section{INTRODUCTION}

We tried to develop the new process of making use of the uniform material, which is often wasted in large quantities at a time under the circumstances peculiar to the uniform industry. Most of the uniform material is the mixture of wool and polyester, which is stronger than the material for general clothes, and its quality is steadier. However, it is difficult to recycle it for the usages other than the cloth. The reason is that wool as a natural fiber has poor durability and perishable, though polyester as the synthetic material of oil origin is strong. So the greater part of the wasted material has been incinerated without recycling.

We repeated the experiment of various processes to find out the way to made up the weak point of wool polyester mixture, maintaining its good points. As a result, it turned out that the material gets more tensile strength, durability against ultraviolet rays, water absorbing property through the process of compounding by soaking in biodegradable resin PVA, which is the water soluble synthetic high polymer.

These are the functions which are very suitable for materials for agriculture and for the gardening greening, so it will be possible to divert them to the multi seat for agriculture which has an excellent durability. And by utilizing these functions, we devised "flower mat" (see Fig. 1) from scrap of clothe, which is light and easy to handle.

"Flower mat" for the plant cultivation fills a basic function only with the PVA soaking but it gets moldy when used indoors because it is wool mixture (see Fig. 2 ). The beauty is spoiled and mold is unsanitary. So, it is necessary to add the anti-bacterial agents to prevent the growth of mold. It is general to use agricultural chemicals such as the Captan medicines for the plant, though we have to think about safety for health in top priority because we use the flower mat by hand. We used two materials, that is (1) Hiba oil, which is of natural origin, and safe for health. So it is used for food and also for the interior design articles. (2) Wood vinegar oil(Mokusaku oil), which is produced when wood is incinerated, and is used as a principal ingredient of the medicine for intestinal disorders due to the strong anti-bacterium revitalization effect for the human body. We made these two oils water soluble and combine them with PVA to test it. [1]

The character of PVA greatly changes with the polymerization level. Though the main material of uniform is the mixture of wool and polyester, the rate of mixture is varied, and it is especially processed. Our research until now shows that the uniform material which is made compound with PVA, improved qualities so far, for example, strength increased 1.5 times etc. [2] And we attempted for the first time to add biomass anti-bacterial oil to this process. As Hiba oil and wood vinegar oil have different qualities, we have expected synergy effect on plus or minus points when mixed with PVA. So we have made the basic researches to get the ratio of an appropriate combination. [3]

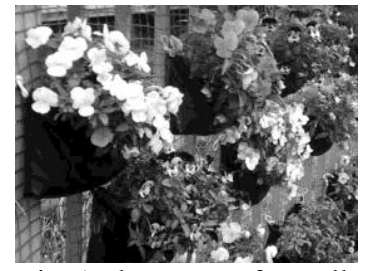

Fig. 1 Flower mat for wall greening

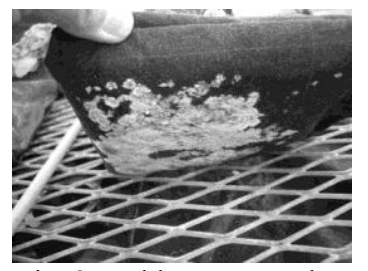

Fig. 2 Mold grown on the back side of flower 


\section{EXPERIMENTAL METHODS}

2.1 Experimental materials

We used polyglycerin-fatty-acid-ester (DECAGLYN 1-L:Nikko Chemicals Co. Ltd. HLB=15.5) which is a hydrophile emulsifier with an extremely high HLB (Hydrophile-Lipophile Balance) value to make wood vinegar oil and the Hiba oil water soluble. There is no preceding research about compound of wool polyester mixture and the PVA resin and water soluble wood vinegar oil or water soluble Hiba oil. As we could not predict the results, we made a high consistency mixture liquid, so that the merits of both biomass anti-bacterial oil and the PVA resin might appear remarkably.

We set up the wood vinegar oil and the Hiba oil in extremely high consistency of $10 \%$ respectively, and we used the PVA resin solution in four kinds of polymerization level $1000,1700,2500,3300$. These are all completely saponified and water soluble. The consistency of level 1000, 1700 is $10 \%$, and that of level 2500,3300 is $5 \%$. We varied the percentage of resin in 6 sorts, from $10 \%$ to $60 \%$, and made the 48 solution sample ( 24 wood vinegar oil and 24 Hiba oil). With this solution sample, we made soaking process to the three kind of material, $\mathrm{A}$ (wool 100\%), B(wool $70 \%$ and polyester $30 \%$ ) and $\mathrm{C}($ wool $40 \%$ and polyester $60 \%$ ) respectively, and made a sample of material by combining them.

2.2 Comparison of amounts of fixation according to percentage of wool polyester mixture

We weighed each uniform material of A, B, C before and after the soaking process, and compared the amount of fixation. Each material is woven in the same way and in same size of yarn and differs in the percentage of mixture. The PVA resin has a lot of hydroxyl group(-OH) in the molecule, and is assumed that it is compatible with a natural material. We took pictures in SEM (scanning electron microscope) photograph to observe the state of fixation.

2.3 Examination of tensile strength when PVA resins of different polymerization level are mixed with water soluble wood vinegar oil

It has already turned out by the experiment that strength of the uniform material increases greatly when it is soaked in the PVA1700. We made the tensile test to gauge what effect is caused by the different polymerization level when the PVA resin is mixed with water soluble wood vinegar oil. The experiment was made only with water soluble wood vinegar oil because it had turned out beforehand that the Hiba (cypress) oil did not infiltrate well into the fiber of $\mathrm{C}$ material whose percentage of wool mixture is low and it could not be processed well.

\subsubsection{About samples}

We made the tensile test, using wool polyester mixed fiber of B material (wool $70 \%$ and polyester $30 \%$ ) which is generally sold in the uniform market. The ratio of wood vinegar oil to PVA resin solution is 4 to 6 , and the polymerization degree of PVA is sorted in 4 level, from 1000 to 3300 . We made the six kinds of samples, as the table 1 shows. We made the ratio of PVA very high to make the difference of the polymerization level clear.

Table 1 Samples for tensile strength test (with material B)

\begin{tabular}{|l|}
\hline 1) Water soluble wood vinegar oil and PVA1000 \\
\hline 2) Water soluble wood vinegar oil and PVA1700 \\
\hline 3) Water soluble wood vinegar oil and PVA2500 \\
\hline 4) Water soluble wood vinegar oil and PVA3300 \\
\hline 5) Water soluble wood vinegar oil only \\
\hline 6) Unsoaked B material \\
\hline
\end{tabular}

\subsubsection{Shape and size of the test piece}

We prepared the strips of cloth, $80 \mathrm{~mm}$ in the total length, $15 \mathrm{~mm}$ in width, $60 \mathrm{~mm}$ in length of gauge, and $10 \mathrm{~mm}$ of the grip part, referring to the JIS L $1096 \mathrm{~A}$, labeled stripping method.

\subsubsection{Method and condition of the examination}

The tensile test was made at the atmospheric normal temperature and at the speed of $3 \mathrm{~mm} / \mathrm{min}$ with a small desk-top examination machine made by JT Torshi Co.,Ltd.

\subsection{Water absorption examination}

If the soaking process is uneven, it may influence the result. So we made soaking process again carefully to the B material by using the solution. We repeated the soaking process twice to make uniformity by soaking and squeezing with the roller vertically and horizontally with a mangle apparatus and dried the samples using the dryer at $60^{\circ} \mathrm{C}$.

The examination method we applied here is JIS L 1907:2010.7.1.1.the dropping method, and the mean value of five samples was taken.

In this experiment we measured the time required from dripping water to the sample, to the time it was absorbed. The sample which requires the less time has the better quality of water absorption.

\subsection{Examination of anti-bacterial activity}

Wool easily gets moldy, and PVA also need anti-mold measures. So we researched by the experiments how the compound with wood vinegar oil or Hiba oil can get anti-bacterial activity. The principal ingredients of wood vinegar oil and Hiba oil are shown in the Table 2.

We chose some kinds of mold grown on the flower mat by which we grew the plant at the Tokyo Metropolitan Agriculture and Forestry Research Center and by repeating culture, purified them and used for the test.

We cultured fungi and bacteria in $37^{\circ} \mathrm{C}$ medium of the potato dextrose agar respectively for five days and spread them on the medium, set the following (see Table 3) seven kinds of samples at room temperature, thus the experiment was executed. We observed it by watching one month later and two months later. 
Table 2 Principal ingredient of biomass anti-bacterial oil (wood vinegar oil, Hiba-oil)

\begin{tabular}{|c|c|}
\hline $\begin{array}{l}\text { Principal ingredient } \\
\text { of wood vinegar oil }\end{array}$ & $\begin{array}{l}\text { Phenol,2-methylphenol,4-methyl } \\
\text { phenol,4-Methylguayacol } \\
\text { 4-Ethylguayacorl }\end{array}$ \\
\hline $\begin{array}{l}\text { Principal ingredient } \\
\text { of Hiba-cypress oil }\end{array}$ & $\begin{array}{l}\text { (aromaelement)Thujopsene, } \\
\text { Cedro, (anti-bacterium element) } \\
\text {,Hinokitiol, } \beta \text {-Dolabrin, and } \\
\text { Citronellic acid [4] }\end{array}$ \\
\hline
\end{tabular}

Table 3 Samples for anti-bacterial test (with material B)

\begin{tabular}{|l|}
\hline 7) Unsoaked B material \\
\hline 8) PVA1700 \\
\hline 9) PVA2500 \\
\hline 10) Water soluble wood vinegar oil and PVA1700 \\
\hline 11) Water soluble Hiba oil and PVA1700 \\
\hline 12) Water soluble wood vinegar oil and PVA2500 \\
\hline 13) Water soluble Hiba oil and PVA2500 \\
\hline
\end{tabular}

\section{RESULTS AND DISCUSSION}

3.1 Comparison of amounts of fixation by the percentage of wool polyester mixture

We compared the weight increased by the soaking process of three materials (A,B,C) (see Fig.3) of the same specification and of different mixture rate, to the PVA resin. As a result, it has become clear, as you see in the table 4 , that the higher the rate of wool mixture is, the more the amount of fixation increases.

The natural fibers are mainly composed of five elements, that is, carbon, hydrogen, and oxygen of the vegetable fiber, and to add to this, nitrogen and sulfur of the wool. It is also a characteristic of PVA, which is assumed to be compatible with natural material. [5]

Moreover, it seems that the difference of the amount of fixation of wood vinegar oil and the Hiba oil is from difference of their viscosity. Wood vinegar oil is extracted from wood tar with high viscosity, and Hiba oil is of the origin of refined oil with low viscosity.

Table 4 Comparison of weight of mixture-materials increased after the process

\begin{tabular}{|l|l|}
\hline A material + Water soluble wood vinegar oil & $121 \%$ \\
\hline B material + Water soluble wood vinegar oil & $117 \%$ \\
\hline C material + Water soluble wood vinegar oil & $111 \%$ \\
\hline A material + Water soluble Hiba cypress oil & $116 \%$ \\
\hline B material + Water soluble Hiba cypress oil & $115 \%$ \\
\hline C material + Water soluble Hiba cypress oil & $110 \%$ \\
\hline
\end{tabular}

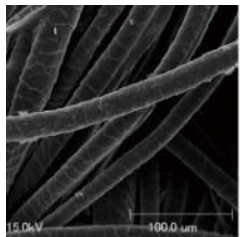

(A material)

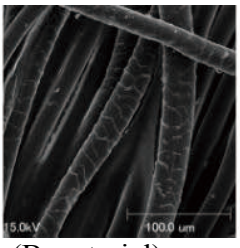

(B material)

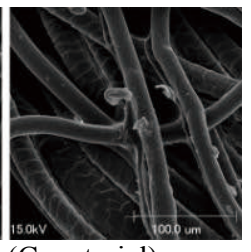

(C material)
Fig. 3 Wool polyester mixed fiber processed by soaking in water soluble wood vinegar oil SEM photograph (magnified 500 times) A material(wool 100\%) B material(wool $70 \%$, polyester $30 \%$ ) $\mathrm{C}$ material(wool $40 \%$, polyester $60 \%$ )
3.2 Examination of tensile strength by difference of each polymerization level

We examined tensile strength by difference of each polymerization level when PVA resins of different polymerization level are mixed with water soluble wood vinegar oil. Table 5 shows the mean value of tensile strength converted into the pressure of every sectional area, and Figure 4 shows the relation between time and stress of the typical test piece converted by the unit. The sectional area which had been used for the unit is the mean value of three points (center and both ends within the length of the gauge) of width and thickness.

Table 5 Tensile strength converted by the unit of the samples

\begin{tabular}{|l|c|c|c|c|c|c|}
\hline $\begin{array}{l}\text { Sample } \\
\text { number }\end{array}$ & 1 & 2 & 3 & 4 & 5 & 6 \\
\hline $\begin{array}{l}\text { Mean } \\
\text { value(MPa) }\end{array}$ & 346.8 & 334.5 & 317.6 & 309.1 & 291.1 & 297.2 \\
\hline
\end{tabular}

Note: the values are converted to the maxim load per unit area.

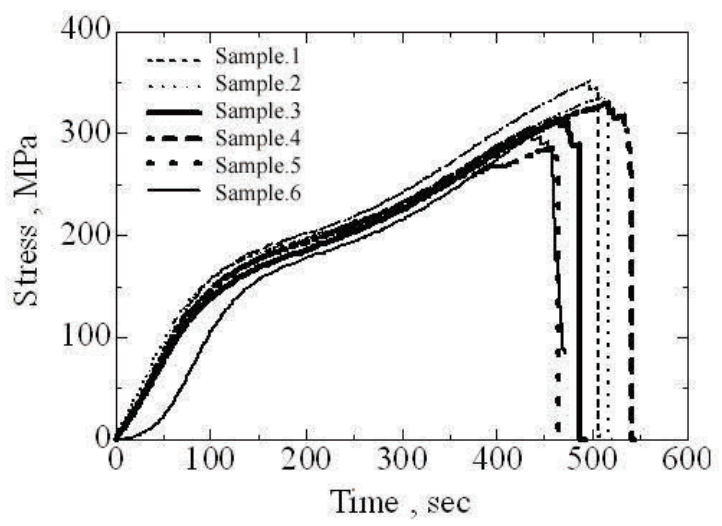

Fig. 4 Relation between time and stress of each test piece (tensile speed $100 \mathrm{sec}$ is converted to $5 \mathrm{~mm}$ )

It has turned out that the combination of PVA sample.1 and sample. 2 has good effect from the point of strength, and combination of sample. 4 is good from the point of toughness because it stretches more than sample. 1 or sample. 2 .

\subsection{Water absorbing property}

Unprocessed wool is water-repellent. The feature of wool is an epidermal cell which is called cuticle with which the surface of the fiber is covered like the scale. Fig.5 shows the unbleached merino wool (magnified 2000times). Fig.6 shows merino wool after processed by PVA 5\% (magnified 2000times). This structure is divided into three layers, and the outermost layer is called epicuticle, which is a very thin film and has hydrophobic property. The epicuticle keeps the wool water-repellent for longtime. [6]

As the table 6 shows, water absorbing property increases from seven to ten times by giving the PVA soaking process. This is because PVA has an excellent hydrophile property, and it adheres to the surface of wool and polyester, and it also adheres to the small space of the fiber.

Moreover, it has become clear that water absorbing 
property increases about two to three times by adding the Hiba oil and wood vinegar oil to PVA.

Table 6 The examination of time for water absorption by different samples

\begin{tabular}{|l|r|}
\hline Sample (processed with material B) & $\begin{array}{l}\text { Time of } \\
\text { water } \\
\text { absorption } \\
\text { (second) }\end{array}$ \\
\hline Only water soluble wood vinegar oil & 215 \\
\hline Water soluble wood vinegar oil+PVA1000 & 156 \\
\hline Water soluble wood vinegar oil+PVA1700 & 275 \\
\hline Water soluble wood vinegar oil+PVA2500 & 114 \\
\hline Water soluble wood vinegar oil+PVA3300 & 275 \\
\hline Only water soluble Hiba oil & 426 \\
\hline Water soluble Hiba oil PVA1000 & 449 \\
\hline Water soluble Hiba oil PVA1700 & 612 \\
\hline Water soluble Hiba oil PVA2500 & 126 \\
\hline Water soluble Hiba oil PVA3300 & 1,370 \\
\hline PVA1700 & 1,041 \\
\hline PVA2500 & 10,463 \\
\hline B material not processed by soaking & \\
\hline
\end{tabular}

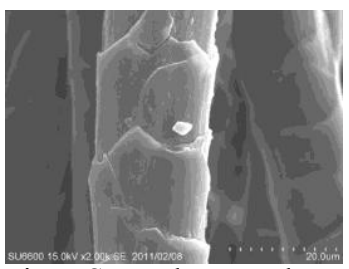

Fig. 5 SEM photograph

of unbleached merino wool after processed by PVA (magnified 2000 times) 5\% (magnified 2000 times)

\subsection{Anti-bacterial test}

It has been clarified that the wood vinegar oil and Hiba oil have anti bacterial activity and make obstruction circle to mold and bacteria in the soil. The way that the effect diffuses is different according to the polymerization level of PVA which is made compound. Compared with PVA2500, the polymerization level of PVA1700 is lower, but its effect extends more to the medium, its obstruction circle is larger, and its anti-bacterial activity continues longer. The following is the result of anti-bacterial test. Table 7 shows the arrangement of samples (B-material) for anti-bacterial test. According to the table 7 , we set the samples on the medium applied by fungi (see Fig.7) and by bacteria (see Fig.8). The photographs of Fig. 7 and Fig. 8 show the condition one month after spreading fungi/bacteria in the room temperature.

Table 7 Arrangement plan of samples (B-material) for anti-bacterial test

\begin{tabular}{|l|l|l|l|}
\hline \multirow{2}{*}{$\begin{array}{l}\text { 7)Unsoaked } \\
\text { B material }\end{array}$} & 8)PVA1700 & $\begin{array}{l}\text { 10) Water } \\
\text { soluble wood } \\
\text { vinegar oil/ } \\
\text { PVA1700 }\end{array}$ & $\begin{array}{l}\text { 12) Water } \\
\text { soluble Hiba } \\
\text { oil / } \\
\text { PVA1700 }\end{array}$ \\
\cline { 2 - 4 } & \multirow{2}{*}{ 9)PVA2500 } & $\begin{array}{l}\text { 11) Water } \\
\text { soluble wood } \\
\text { vinegar oil } \\
\text { /PVA2500 }\end{array}$ & $\begin{array}{l}\text { 13) Water } \\
\text { soluble Hiba } \\
\text { oil / } \\
\text { PVA2500 }\end{array}$ \\
\hline
\end{tabular}

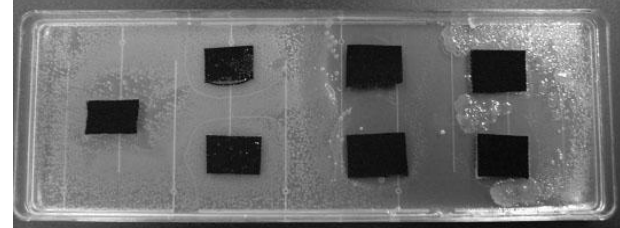

Fig. 7 One month after spreading fungi in the room temperature

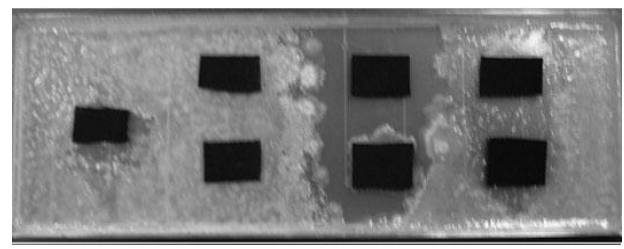

Fig. 8 One month after spreading bacteria in the room temperature

\section{CONCLUSION}

We have made a research how to utilize the uniform material which cannot be reused for cloth material. Our research till now shows that compound of uniform material with PVA improves the properties of the material; i.e. the durability to ultraviolet rays is added and tensile strength increases 1.5 times.

We have experimented for the first time to mix PVA of various polymerization levels with biomass anti-bacterial oil and to make compound with the uniform material. It turned out this process of compound makes the positive synergy effect, and adds the advantage to the performance improvement by the PVA soaking as we expected.

That is, an excellent improvement in water permeability was seen by the compound of the Hiba oil and wood vinegar oil. Especially, it is remarkable for the Hiba oil. This is thought to be a suitable function as a flower mat of the plant cultivation.

The most remarkable point is that the anti-bacterial effect continues apparently for more than two months when made compound with wood vinegar oil. We expect this fact contribute greatly to practical use.

PVA1700 and PVA2500 are strong in quality and easy to process, when it is water soluble, from the point of the viscosity and suitable for compound. We would research the ways of use (for outdoor, indoors etc.) by analyzing the characteristics of wood vinegar oil and Hiba oil.

\section{REFERENCE}

[1] K.Ataka, M.Itoh, T.Shibata, Yakugaku Zasshi, 125(12),937-950(2005).

[2] M.Sekkuden, T.Yamamura, T.Okazawa, K.Goda and T.Okabe, Trans. Mat.Res.Sec.Japan, 37 (1) , 45-48 (2012).

[3] Y.Morita,T.Okabe,K.Kougenji,T.Fukui,K.Fukuda, Wood Preservation, 37(4), 165-170(2011).

[4] T.Okabe,Others, Aomori Hiba-Abura Kenkyukai, 132-136(1990)

[5] M. Abe, Seni kikai Gakkaishi,65(3), 27-35(2012)

[6] M. kaimori, Seni kikai Gakkaishi,65(2), 17-26(2012) 